\title{
Teachers' Perceptions and Practices of Written Feedback in Higher Education
}

\author{
Raisa B. Gul ${ }^{1, *}$, Ambreen J. Tharani ${ }^{1}$, Arusa Lakhani ${ }^{1}$, Nusrat F Rizvi ${ }^{2} \&$ Syeda K. Ali ${ }^{3}$ \\ ${ }^{1}$ School of Nursing and Midwifery, Aga Khan University, Karachi, Pakistan \\ ${ }^{2}$ Institute of Educational Development, Aga Khan University, Karachi, Pakistan \\ ${ }^{3}$ Department of Educational Development, Aga Khan University, Karachi, Pakistan \\ *Correspondence: School of Nursing and Midwifery, Aga Khan University, Karachi, Pakistan. E-mail: \\ ambreen.tharani@aku.edu
}

Received: March 15, 2016

Accepted: April 18, 2016 Online Published: May 18, 2016

doi:10.5430/wje.v6n3p10

URL: http://dx.doi.org/10.5430/wje.v6n3p10

\begin{abstract}
This mixed-methods research aimed to understand the practices and perceptions of teachers regarding written feedback. For this purpose, a survey was administered to 150 teachers forming a non-probability sample, who were working in various universities in Karachi. The disciplines chosen for the study included nursing, applied linguistics, medicine and education departments in institutes of higher education situated in Karachi. Before sampling, initial screening was done to obtain a list of institutes which provide written feedback on students' assignments. Two homogenous groups of teachers by discipline (nursing and education) were then selected for focus group discussions. It was found that most teachers consider written feedback an important tool for guiding and helping students improve their work. In fact, they consider written feedback as important as verbal feedback. Teachers also recognized the importance of discussing the written feedback with the students but they rarely did so because of time constraints. Most teachers preferred to directly fix students' errors instead of providing feedback to enable them to correct those errors by themselves. While less than half of the participants used a checklist for grading, others used annotation. Several factors were found to have a great influence on the amount and quality of feedback. The most significant factor was whether teachers had formal training in providing feedback. Only $17 \%$ of the participants in this study had proper training to give written feedback. They also identified several environmental and personal factors that had an impact on their feedback practices including time, the relationship between the teacher and individual students, and, most importantly, the policies and culture of the institutes.
\end{abstract}

Keywords: written feedback; form; perceptions; content; practice

\section{Introduction}

One of the features that sets tertiary education apart from secondary is the fact that it requires a lot of writing. Students in tertiary education need to write original, argumentative and concise academic papers in English, which is usually not their mother tongue. This creates huge challenges for students especially from developing countries such as Pakistan as they do not get appropriate and individualized support in developing their English writing skills in secondary schools. In universities, without adequate and effective feedback on their writing, students may not develop their academic writing skills and consequently they turn to plagiarism and other malpractices. In such a scenario, the role of written feedback assumes critical importance, because it helps students learn about their strengths and weaknesses (Corcoran, Halverson, \& Schindler, 2014; Giles, Gilbert, \& McNeill, 2014; and Orrell, 2006) and build their competence in academic writing.

The literature on written feedback (WFB) is abound with definitions of the term. Some define it simply as teachers' response to learners' writing (Gul \& Rodrigues, 2012). Others state that it includes error correction, underlining or written comments (Lee, 2009). Certain definitions focus on its aims such as acknowledging students' strengths and weaknesses and guiding them on how to improve (Iqbal, Gul, Lakhani \& Rizvi, 2014), and to help teachers decide what grade to assign (Maclellan, 2010).

While it remains valid that the content and manner of academic writing depends to a great extent on the specific field 
of study (Bailey \& Vardi, 1999), there is still a certain benchmark for academic writing that is common to all disciplines. Based on this assumption the present study was undertaken with a multidisciplinary approach. Assuming that there is a common core of writing regulations that teachers from all these fields adhere to when providing written feedback to students on their written assignments, this study explores the practices and perceptions regarding feedback of teachers from medicine, education, nursing and applied linguistics. The present paper stems from the first phase of a large-scale study on WFB in higher education institutes in Karachi, Pakistan.

Feedback does not operate in a vacuum, and in fact, the quality and nature of WFB is affected by a number of contextual factors. These include teachers' knowledge skills, disposition, as well as their relationship with the learners. Another consequential factor is the openness and responsiveness of individual students towards feedback. Teachers are naturally encouraged to provide quality WFB when they see students incorporating the teacher's advice in their subsequent work, and discouraged when students appear to ignore it. The culture of the institute has also been found as a key factor which influences practices of WFB. For instance, workplace arrangements and teachers' workload matter, since sharing a room with other teachers can obviously be distracting. Notably, pressures for good grades from influential/aggressive students and/or stakeholders impinge strongly on teachers' provision of WFB. In such circumstances, teachers also find it challenging to align grades with feedback (Lizzio \& Wilson, 2008). Institutional policies, or the lack thereof, could be another inhibiting factor (Iqbal et al., 2014). It is a well-documented fact that most institutions in Pakistan do not offer official guidelines or policies as to how teachers should provide WFB (Iqbal et al.; Khowaja \& Gul, 2014). In such a scenario, teachers develop idiosyncratic feedback practices.

Newton's (2008) research clearly highlights the importance of having a consistent policy of feedback. In a case study of a nursing faculty's endeavours to improve their understanding of writing guidelines in order to help students, Newton found that many of the teachers were uncertain whether to evaluate students' papers strictly according to the APA style manual. They resisted on the grounds that students' assignments are just assignments and are not meant for publication. Another reason for irregularity among teachers' WFB on the paper was that the individuals who were teaching in the school of nursing were from varied scientific disciplines with varied qualifications. Due to this, students received varying instructions on writing from separate teachers, which is likely to have made them regard writing as a meaningless task, contrary to the rigorous and consistent practice they had in clinical laboratory courses.

The most significant factor found to affect feedback is teachers' competence. Newton (2008) postulates that if teachers themselves are not proficient in the required writing style, they cannot provide students with accurate feedback on their writing. Recent studies (Iqbal et al., 2014; Poulos \& Mahony, 2008; Schartel, 2012) also demonstrate that teachers' professional development in the area of providing feedback has the strongest influence on the nature and effectiveness of their WFB. Such findings lead to the conclusion that teachers who are properly trained in providing feedback will be in a better position to guide their students.

Other than teachers' expertise, their beliefs about teaching and learning also influence their feedback practices. In fact, teacher's views and practices are the crux of the matter in a classroom, because they underlie their overall teaching and learning approaches (Griffiths, 2007). The present study thus sought to learn more about how higher education teachers in the Pakistani context perceive of and provide WFB, and what factors influence their practice. Our ultimate aim was to use the data from the present study, coupled with the literature review on WFB, to design a context-specific interventional workshop to enable higher education teachers to develop a clearer understanding of effective WFB and improve their practice accordingly.

\subsection{Research Questions}

To be specific, this study aimed to answer the following questions:

1. What are the teachers' perceptions of written feedback?

2. What are the teachers' practices of providing written feedback?

3. What factors affect teachers' practices of providing written feedback?

\section{Literature Review}

\subsection{Utility, Purpose and Focus of WFB}

Many recent studies have proven the usefulness of WFB (Corcoran et al., 2014; Giles et al., 2014; Koh, 2010; and Rogers et al., 2012). Bailey and Vardi (1999), for instance, demonstrated the beneficial effects of feedback through their case study of a cycle of feedback in formative assessment. It was observed that the teacher's feedback helped 
the student under study improve, increasing his grade by $20 \%$. The student took note of the feedback and made changes accordingly, with respect to content, theme and overall structure, thus helping him progress. Their study is interesting in that it supports Sitko's (1993) assertion that improvement is not a result only of feedback, but is something that occurs when students actively utilize the feedback (in Bailey \& Vardi, 1999).

However if the teachers do not have consistent and clear criteria for marking, it is unlikely that students improve their writing. For instance, Bailey and Garner (2010) interviewed 48 university teachers in the United Kingdom regarding their perceptions of WFB and discovered wide divergence among various teachers' beliefs about feedback. The teachers were even unsure of the purpose of providing WFB.

While there is general consensus that the purpose of WFB "is to help students develop the ability to monitor, evaluate and regulate their own learning" (Nicol, 2010, p. 504), one of the central questions in WFB remains whether feedback should focus on form (language) or content (subject matter) (Fathman \& Whalley, 1990). Ferris (2006) observed that teachers are divided on the opinion of whether to focus on writing style, vocabulary and word choice, surface structure such as grammar and mechanics, or on overall structure and content.

Similarly, it is controversial whether feedback should focus on correction or alternatively, provide suggestions for correction. For instance, Glover and Brown (2006) conducted a study in the United Kingdom spanning the opinions of both teachers and students, and found that teachers' feedback usually focused on error correction rather than on providing suggestions for improvement. Nevertheless, many studies have demonstrated that even teachers who claim that content is as important as form, and corrections are as crucial as suggestions, actually focus on one of the two.

\subsection{Teachers' Perceptions and Their Practice}

It has been generally observed that there is not always a great degree of fit between how teachers conceptualize feedback and how they actually provide it (Orrell, 2006). Several researchers have sought to make connections between teachers' views on feedback with their practice.

Lee (2009) conducted one such study in Hong Kong and discovered many disparities between EFL (English as a Foreign Language) teachers' beliefs $t$ and their actual practices of giving feedback. Teachers' practice was observed by analyzing the feedback of a convenience sample of 26 teachers on 174 samples of students' writing and then interviewing seven of those teachers. To understand their beliefs, the researcher administered a questionnaire to a convenience sample of 206 secondary teachers and then interviewed 19 of them. Lee found that even though teachers claim that effective writing involves more than accuracy, they usually focus on form only. Similarly, they claim that selective feedback is better, and that students should be able to trace and correct their own errors, but they give comprehensive feedback which may make things too easy for students to the extent that they do not invest their time and effort to diagnose their errors in the light of feedback and correct them. Even though teachers believe that error codes confuse learners and marks distract learners from feedback they still use codes and award marks. Additionally, teachers claim that WFB should cover both strengths and weaknesses but they mostly provide critical feedback; that is, feedback that focuses on weaknesses. It was also found that teachers continued to highlight students' errors without providing much support to them regarding how to improve those errors, despite the fact that most of them believed that the effort was futile as students did not appear to learn from their mistakes.

In a similar vein, Gul and Rodrigues (2012) studied the feedback of a Pakistani ELT teacher and found that even though the teacher believed that she modified the focus of her feedback depending on the type of writing task, in reality she focused mostly on surface errors such as grammar and mechanics. The researchers analysed samples of four students' writing for three months and also interviewed them. They concluded that because the teacher's feedback focused on grammar and mechanics, the students likewise saw writing as a robotic task of accuracy instead of as a means of creative communication. Interestingly, the feedback did not have a very negative backwash effect because students were indeed improving in the areas focused on by the teacher, although no improvement was observed in terms of content, relevance and structure, etc.

Interestingly, another study of WFB in Karachi, Pakistan found discrepancies between teachers' professed views of feedback and their provision of it. Iqbal et al. (2014) interviewed a purposive sample of 12 nursing teachers from five separate institutes. They discovered that even though all the teachers acknowledged the need for WFB to be worded positively, they confessed to not always applying this approach. While emphasizing the need for feedback to be clear, teachers admitted that it often was not clear to students unless verbally reinforced. In addition, there was disagreement about whether critical feedback should be direct or polite. Despite the fact that teachers' practice was not directly observed via analysis of samples, their study clearly indicates the tendency for teachers to report beliefs that do not appear to be in line with their feedback practices. 
Conversely, it is not always the case that teachers' practices belie their beliefs. Brown, Harris and Harnett (2012) undertook the task of analyzing the perceptions and practices of feedback of $(n=518)$ teachers in Auckland. They devised a questionnaire titled the Teacher's Conceptions of Feedback (TCoF) enquiring about the purposes and types of feedback, and the literature on feedback. To find out about their practice, the teachers were then provided with a list of 17 different types of feedback of which they had to select all that applied to their own method. Analysis revealed that teachers felt students improve most through the use of formative feedback, that feedback should be encouraging, that it is relevant and useful, and finally, that self-feedback (evaluation of one's own work) and peer-feedback (evaluation of one's work by a peer) were also beneficial.

\subsection{Teachers' Perceptions versus Students' Perceptions}

Problems can arise even in situations where teachers' practices are aligned to their beliefs, if they clash with those of the students. Carless (2006); for instance, discovered vast disparity between teachers' and students' ideals of feedback. Jodaie, Farrokhi and Zoghi (2011) also compared and contrasted students' and teachers' views on feedback. Questionnaire and interview responses of $(n=110)$ Iranian students and $(n=38)$ teachers revealed some variation in their opinions. For example, students that felt feedback must be given on every draft while teachers were divided in their opinion of whether it should be given on the first, second or last one. Also while over $80 \%$ of the students voted for detailed feedback, a comparatively smaller percentage of teachers, $57 \%$ voted for it. The researchers suggested that WFB can be debilitative if students' and teachers' views on the matter are incongruent with one another, hence both groups should learn about and work through each other's preferences.

This is why WFB works best in circumstances where students have the opportunity to discuss it so that they may clear up confusions and ambiguities. If students are not given this chance, they usually look to their classmates for help (Ghazal, Gul, Hanzala, Jessop, \& Tharani, 2014) who might not always be able to point them in the right direction as they might themselves be misled.

\subsection{The Need to Train Teachers}

Nevertheless, one must remember that it is not only students who may be misled. In higher education, teachers are hired on the basis of their subject knowledge but they usually lack basic knowledge about the theories behind feedback and also the basic skills required to provide it (Schartel, 2012). Student participants in Khowaja, Gul, Lakhani, Rizvi and Saleem (2014) shared a similar view. They felt that their teachers may be experts in their field but are inexperienced with respect to providing written feedback. Khowaja et al. propose that this might be caused by low levels of English proficiency among faculty members. The incompetence of teachers can be extremely detrimental to students' progress. They are bound to be very demotivated when they feel that their teacher does not have enough proficiency to provide useful feedback on their writing. In this vein, the graduate students in Ghazal et al.'s (2014) sample expressed the concern that their teachers are not adequately trained in the provision of WFB. These studies delineate the importance of having teachers develop their skills of providing written feedback before they are required to facilitate their own students' written assignments with WFB.

\section{Research Method}

As mentioned earlier, this paper was part of a larger project on WFB across various disciplines in higher education institutes in Karachi. For the purposes of the present paper, 150 teachers were selected from four disciplines: nursing, medicine, applied linguistics and education. A mixed-methods approach, using a questionnaire and focus group discussions, was used to discover teacher's perspectives on and practices of feedback.

\subsection{Data Collection}

Two sources of information were used to triangulate the findings: a questionnaire survey and focus group discussions. Initially, data were collected using a questionnaire that was self-developed but based on a thorough review of the literature (Brown et al., 2012; Fathman \& Whalley, 1990; Ghazal et al., 2014; Khowaja \& Gul, 2014; Lee, 2009). The questionnaire was divided into three sections. The first section contained questions aiming to collect demographic information such as age, gender, qualification, and experience. The second section consisted of 22 questions employing a 3-point Likert scale of agreement regarding teachers' perceptions of feedback. The last section targeted teachers' practices; it contained 22 questions on a 3-point Likert scale of frequency. The questionnaire was validated and piloted prior to the data collection. Data gathered from the questionnaire were triangulated with the help of two focus group discussions. The participants were asked six broad questions in the course of a two-hour discussion. Two questions related to their views on WFB, particularly the purpose and nature of WFB. Three questions addressed their own practice, specifically their area of focus, their communication of assignment writing 
guidelines, and the factors that influenced their provision of WFB. Lastly, the participants were asked to suggest ways to improve teachers' understanding of WFB.

\subsection{Sampling}

A screening tool along with an information letter was sent to higher education institutes in Karachi. The form consisted of eight questions enquiring about the level of programmes (graduate/undergraduate, and so on), details of formal written assignments from students and expectation of WFB from teachers on those assignments.

Next, using non-probability sampling, a total of 150 teachers from four disciplines participated in the survey stage of the study. They had been teaching for an average of 11 years. Details about the proportion of teachers from each discipline, their gender, age and qualification are shown in Table 1.

Table 1. Proportion of Teachers in Sample

\begin{tabular}{cccccccc}
\hline DISCIPLINE & $\%$ & GENDER & $\%$ & AGE & $\%$ & QUALIFICATION & $\%$ \\
\hline Nursing & 51 & & & & & & \\
Education & 40 & Female & 62 & 20 to 30 years & 22 & Bachelors & 24 \\
Applied Linguistics & 5 & Male & 38 & 31 to 40 years & 38 & Masters & 57 \\
Medicine & 4 & & & Over 40 years & 40 & Post-Masters & 19 \\
\hline
\end{tabular}

Two homogenous groups of participants by discipline were selected for focus group discussions, conducted by the members of the research team. All five participants in the first group were from nursing and the four in the second were from education. Although the researchers planned to have focus groups from medicine and linguistics as well, the teachers from those groups remained unavailable despite repeated efforts to assemble them.

\subsection{Data Analysis}

The quantitative data from the survey were entered and checked for accuracy and consistency with the help of EPI-Info software; version 6.04. Expert data entry operators double-entered the data, and to ensure its validity, files were compared and rechecked. Descriptive statistics were performed to synthesize the data from the survey, the calculations including frequency distributions, measures of central tendencies and variability.

The qualitative data from the focus group discussions were recorded, transcribed verbatim and were then manually categorized according to the three themes in the survey questionnaire (Creswell, 2008).

\subsection{Ethical Considerations}

A strict code of ethics was observed throughout the research. Institutional participation was secured via letters of informed consent. Participants of the focus group discussions were also asked to sign letters of informed consent so as to ensure that they were not misled or coerced into participation. As for the survey, return of the completed questionnaire was presumed to demonstrate willing participation. Additionally, confidentiality and anonymity of all the participants was ensured by using codes instead of names during data collection and analysis.

\section{Findings}

First, the results of the survey will be outlined and then the data from the focus group discussions will be described.

The first section of the questionnaire covered the demographic profile of the participants, which has already been summarized in the table above. Another important question in this section was how the teachers learned about WFB. Under this question the respondents were given a range of options, of which they had to tick all that applied. An overwhelming but unsurprising $85 \%$ of the teachers said they learned through trial and error, while $82 \%$ claimed to have learned via observation of the way their own teachers gave them feedback. A much smaller minority of $29 \%$ said they had learned from peers and only $17 \%$ claimed to have had any formal training/course on providing WFB.

The second section of the questionnaire uncovered information about respondents' perceptions, mainly focusing on four areas: their purpose of providing WFB, the way they expected students to respond, how they conceptualized WFB, and factors affecting the quality of their feedback.

Factors affecting the quality of teachers' feedback emerge clearly from table 2. Interestingly, even though very few of the participants had received any formal training in WFB, an overwhelming majority of them felt that such training was the primary factor that can affect the quality of their WFB. Other important factors included the teacher's workload and environmental distractions. 
The results of this section are summarized in Table 2 .

Table 2. Teacher's Perceptions about WFB

\begin{tabular}{lccc}
\hline \multicolumn{1}{c}{ PURPOSE OF PROVIDING WFB } & Disagree & Neutral & Agree \\
\hline Justify the marks/grades & 12.1 & 7.0 & 80.9 \\
Communicate the gaps in performance & 5.1 & 7.6 & 87.3 \\
Communicate teachers' expectations & 4.5 & 8.9 & 86.6 \\
Help students to self -assess their performance & 1.9 & 6.4 & 91.7 \\
Institutional policy & 1.9 & 6.4 & 91.7 \\
\hline \multicolumn{1}{c}{ ANTICIPATED STUDENTS' RESPONSE } & Disagree & Neutral & Agree \\
\hline Ignore comments and consider grades & 51.6 & 11.5 & 36.9 \\
Critical feedback demotivates students & 51.6 & 17.2 & 31.2 \\
Students improve work after feedback & 5.7 & 7.6 & 86.6 \\
\hline \multicolumn{1}{c}{ CONCEPTION OF WFB } & Disagree & Neutral & Agree \\
\hline Equally important as verbal feedback & 3.8 & 7.0 & 89.2 \\
WFB should focus on good work rather than areas of improvement & 61.8 & 10.2 & 28.0 \\
Remarks should be compatible with marks & 8.3 & 9.6 & 82.2 \\
\hline \multicolumn{1}{c}{ FACTORS AFFECTING QUALITY OF WFB } & Disagree & Neutral & Agree \\
\hline Teachers' training for providing feedback & 6.4 & 7.6 & 86.0 \\
Workload of the teacher & 19.1 & 9.6 & 71.3 \\
Environmental distractions & 18.5 & 13.4 & 68.2 \\
Student-teacher relationship & 35.7 & 13.4 & 51.0 \\
Comments are influenced when teacher knows the student & 28.0 & 14.0 \\
\hline
\end{tabular}

The third section of the questionnaire covered four main aspects of teachers' practice of WFB: the provision of WFB, their approach for correcting errors, the mechanics of the feedback, and opportunities for clarification.

It was found that most teachers return marked assignments to their students. Only a minority of the sample said they provide marks without giving WFB. The majority of the participants reported that they directly corrected errors while very few claimed to only indicate the errors without correcting them. Almost all the teachers provided the comments in the context they pertained to, while a little under half claimed to use a specially designed checklist. Notably, $78 \%$ of the teachers felt there was no time to discuss their WFB with the students. However; at least one-third of them claimed clearly that they still make the time to verbally discuss their WFB with low-scoring students or students who request further clarification of their feedback.

Teachers displayed awareness of the different types of feedback; coded, direct and indirect, but the most prevalent type of feedback among the sample was direct WFB, in which the teacher directly corrects the student's error. Less than half the teachers claimed to use a grading checklist. The majority provided feedback using a pen/pencil, rather than a computer application. They claimed to be careful to word their WFB positively, and to focus on various areas of the writing, including content, form, relevance, structure and accuracy.

The findings from this section are summarized in Table 3.

Table 3. Teacher's Practice of WFB

\begin{tabular}{lccc}
\hline \multicolumn{1}{c}{ MISCELLANEOUS PROVISION OF WFB } & Least frequently & Sometimes & Most frequently \\
\hline Return all marked assignments & 12.7 & 10.2 & 77.1 \\
Provide marks to students without WFB & 65.6 & 19.7 & 14.5 \\
Provide good grades & 50.3 & 25.5 & 24.2 \\
Feel satisfied with their practices of WFB & 12 & 28 & 58 \\
\hline APPROACH FOR CORRECTING ERRORS & Least frequently & Sometime & Most frequently \\
\hline Highlight errors & 66.9 & 19.7 & 13.4 \\
Carefully word WFB positively & 5.7 & 19.1 & 75.2 \\
Correct errors as found & 14.6 & 20.4 & 65 \\
\hline
\end{tabular}




\begin{tabular}{lccc}
\hline MECHANICS OF WFB & Least frequently & Sometimes & Most frequently \\
\hline Provide comments on relevant pages & 5.1 & 14.6 & 80.3 \\
Use of specially designed checklist/grid & 35.0 & 19.7 & 45.2 \\
Provide comments via email/track changes & 52.9 & 20.4 & 26.8 \\
Use of pencil for WFB & 67.5 & 15.9 & 16.6 \\
\hline OPPORTUNITY FOR CLARIFICATION & Least frequently & Sometimes & Most frequently \\
\hline No time for discussion of WFB & 5.1 & 17.2 & 77.7 \\
Discussion with low graders only & 45.9 & 20.4 & 33.8 \\
Discussion upon request from student & 42.7 & 19.1 & 38.2 \\
\hline
\end{tabular}

It was discovered that the frequency and standard of feedback differed depending on the academic discipline of the participant. Notably, teachers from nursing provided WFB the most frequently, then education and linguistics, and medical ones the least. Overall, $47 \%$ of the survey respondents answered in the affirmative and provided their contact information in the survey section that enquired after their interest in attending a workshop on WFB.

The focus group discussions were analyzed according to the three themes mentioned above. In terms of perception, the same results emerged as in the survey. For instance, a general consensus was observed regarding the importance and purpose of feedback: to help students improve by highlighting their strengths and weaknesses. In fact, as one participant described it, absence of feedback leads to absence of learning:

I just want to add that feedback is very important, if we don't give feedback how would the person know whether there is any lacking, what are their weaknesses, how can they improve? The person would think; 'okay this is perfect [performance] ... there is no room for improvement' ... so there won't be any 'learning' for that person .... So therefore, I think written feedback is very important and very critical [for learning].

In regards to the focus of correction, teachers were of the view that both are important. This is because they felt that there is an unbreakable link between the two, as reflected in the excerpt below:

They [students] actually have problems in language and content so it is very important to give them feedback on their content, on what the student has actually written, and on the errors also. Otherwise they want to write something but the language is not of that quality, it means something different [than what they intend] so we have to ask the student what they mean by their sentence. So it is important. The faculty should give feedback on the content and what is expected of the student and also the language part. The two things are related.

Other important areas of focus were relevance, overall structure and accuracy of referencing. Teachers felt that during feedback they could 1) indicate the problem, 2) suggest a way to solve the problem or 3) completely solve the problem. Which of the three options they chose from the three listed above depended on individual students' needs as well as competence. The survey results, on the other hand, indicated that only $13 \%$ teachers preferred the first option while $65 \%$ chose option three. Teachers claimed that the clearest way to minimize the need for WFB was by communicating their expectations to the students prior to the assignment, for instance, by giving them the marking scheme in written form, as well as explaining it once in the class. Likewise, almost half of the survey respondents claimed to use a marking scheme.

I discuss with them before the assignment, I think this is our practice over here as well, that we talk about specific criteria. 'You will be marked in this specific criteria, this is your written assignment, this is the task that you have to do' and then we also talk about it. Sometimes I have also used rubrics ... for example if I have a large class of 40 students I prefer giving a rubric so that it is easier for them and for me.

The survey respondents highlighted the same concerns as the focus group participants in terms of issues that adversely affect the quality of their WFB. The first was demotivation triggered by the observation that students sometimes fail to respond to feedback. In the words of one participant, "They [students] want the numbers, they aren't concerned about the written feedback. It is better to provide them general feedback.....and discuss it in the class because they are not very concerned about specific feedback."

Another factor was work overload in terms of credit hours and course planning etc., which in turn causes lack of time. Then there was teachers' own experience and knowledge of the content, students' competence as well as teachers' credentials and competence. Institutional policies, such as guidelines for WFB, were also found to matter: "We have 
already made proper guidelines for students, but are there guidelines for the faculty on how to mark assignments? So I think ... the faculty should have guidelines, how to mark the assignments."

Moreover, teachers admitted that institute-specific cultural factors could also impact their feedback, such as the pressure to provide positive feedback and good marks, from students as well as administrators, as explained below:

According to the situation of this city and the mushrooming of schools, the business administrator or the owner of the school wants to upgrade his institute. [They want to claim that] 'Our students are $100 \%$ passing' .... and they say to the faculty 'Don't give feedback, I will give you salary' and 'don't worry [about other things], you just teach your subject.'

Many of the participants felt that teachers' relationship with the individual learner had a great impact on the nature of the WFB. As described below:

One of the factors could be how the teacher perceives a particular student. You know at times there is a comparison which faculty makes between students that "this is an A grade student so his/her assignment will be okay", and if a student is low grader or his/her behavior is not good "His/her assignment will be of low class."

They suggested that pre-assignment discussions of the teachers' exact expectations, coupled with follow-up discussions of their WFB could help the students understand better. Moreover, all the focus group participants expressed a keen desire to be trained in the provision of WFB. In the words of one participant, "We all should know how to give feedback. We are looking forward to a workshop in upcoming days."

\section{Discussion}

The findings from this study corroborate with findings from earlier studies that have explored how teachers perceive feedback. For instance, Iqbal et al. (2014) found that teachers felt WFB was meant to help students improve and should be worded positively (Brown et al., 2012), and the present sample showed the same inclinations. Maclellan (2010) reports that the purpose of providing WFB is to be able to allocate grades and $81 \%$ of the sample in the present study agreed that justification of grades was an important function of WFB. Moreover, the participants believed that students do indeed improve as a result of feedback, as demonstrated in Gul and Rodrigues (2012) even though teachers in some previous studies (Lee, 2009) have displayed more defeatist attitudes towards WFB.

Only a small number of participants in the present study claimed to use codes to highlight errors. Most of them preferred to directly correct errors instead. This coincides with Lee's (2009) finding that the use of codes may confuse students. Furthermore, when it came to the matter of form versus content, teachers in the present study professed to different personal preferences. This is in line with the controversy over form or content noted in earlier studies of feedback (Fathman \& Whalley, 1990; Ferris, 2006; Gul \& Rodrigues, 2012; Iqbal et al., 2014; Lee).

The teachers in the present study provided marks as well as WFB, albeit while being careful that the two were congruent with one another. Lee (2009), on the other hand, opines that marks distract students from WFB which implies that marks should not be provided at all. It is not difficult to conjecture why teachers in this study needed to provide marks and not just WFB. Most written assignments students submit in higher education in Pakistan are part of formal assessment, meaning that they contribute to the total score of the student throughout the term. The purpose of marking such papers is to provide students with a quantitative measure of their progress or lack thereof, which might not otherwise be very clear merely from the number of feedback comments. In contrast, if marks are given without WFB, the opportunity for improvement is lost.

It is worth noting at this point that the hiatus between teachers' reported perceptions and actual practices of providing WFB observed in national and international literature (Gul \& Rodrigues, 2012; Iqbal et al., 2014; Lee, 2009; and Orrell, 2006) was found in two respects in the present study as well. First, consider the fact that participants claimed that time constraints impinge on their ability to verbally explain their WFB. Still, it was gratifying to learn that participants claimed they did manage the time to discuss their WFB with students who scored low or those who requested such reinforcement. Nonetheless, this practice is not prevalent enough to satisfy the findings in Iqbal et al. and Ghazal et al. (2014) that students often require verbal feedback to clarify WFB. Secondly but more importantly, while an overwhelming $86 \%$ of the sample felt that teachers' training was the primary factor affecting the quality of their WFB, only $47 \%$ of the survey respondents showed interest in attending workshops on written feedback. Contrary to that, a majority of the focus group participants showed interest in such training which could be because of personal contact with the research team. 
Another noteworthy finding of the present study was that teachers in nursing provide much more WFB as compared to the remaining three disciplines. Contrary to the researchers' expectations, even teachers in education and linguistics did not provide WFB as frequently, presumably because of personal and contextual factors. There is no support for such claims in the current literature because not many, if any, studies of WFB have taken a multidisciplinary approach. The most obvious possible cause for the divergence is that the sample comprised of more teachers from nursing than other disciplines. Another possible reason that could specifically explain the dissimilarity between frequency of WFB in nursing and medicine might be the difference in assessment practices between the two disciplines. For instance, whereas nursing schools usually require students to submit some term papers, the most prevalent form of written assessment in medicine is the MCQ-based test, based on findings from our screening tool.

Other important factors well-documented in the literature (Ghazal, et al., 2014; Iqbal et al., 2014; Newton, 2008) to have a strong influence on the way teachers provide feedback include institutional policies on WFB, teachers' workload, as well as the culture of the institute on the whole. Teachers' training and qualification also appear to be of significance, as cited earlier in Schartel (2012) and Newton, respectively. An additional mitigating factor was the rapport students have with the teacher, confirming findings from earlier research (Iqbal et al.; \& Khowaja \& Gul, 2014). Half the teachers in the sample confessed being under pressure to provide good marks. This is in line with findings from national literature (Iqbal et al.), demonstrating that influential students and stake-holding administrators often coerce teachers into giving positive feedback and high scores, at least in small private institutions.

This is an alarming finding that can have serious implications. For example, it would either force teachers in need of employment to abandon their values and beliefs or it would result in unemployment of teachers who firmly uphold their beliefs and resist the pressure to grade leniently. As for students, it would not only rob them of the opportunity to learn from their mistakes, but would also grant them false high scores. Ultimately, this would damage the education system as a whole, as institutes continue to generate unworthy candidates and teachers carry on suppressing their morality.

Further investigation needs to confirm whether pressure for positive WFB is a nationwide phenomenon or is restricted to private institutions only. Taking into account the dearth of research on this dimension of feedback in international literature, one must consider the possibility that other studies simply do not acknowledge such factors or that it is found only in specific contexts.

In addition, keeping in mind the constraints on feedback posed in the Pakistani context, there needs to be an examination of how cultural and institutional pitfalls to feedback can be avoided. For instance, perhaps the need for teacher-feedback can be minimized by training students in self-correction. Self-correction refers to the ability to amend and improve one's own writing, based on points of weakness that teachers have outlined previously.

The negative effects of some other of the abovementioned factors can be combated by 1) drafting and implementing a uniform policy of WFB across higher education institutes, and 2) engaging in feed-forward. Feed-forward refers to the practice of giving students feedback on each draft of the assignment, with separate marks allotted for every draft. This increases utilization of the WFB as the final product is a result of multiple stages of feedback. 3) Teachers may give learners precise written instructions about the marking scheme and checklist for grading (rubrics) at the same time as prescription of the assignment so that students may focus on the required areas beforehand. This is in line with Gul and Rodrigues' (2012) suggestion that students can be empowered if they are made to master the art of self-correction. Gul and Rodrigues also recommend that WFB should be consistent and that students' development should be recorded so that future writing lessons may be planned accordingly.

In general, there is great scope in the field of WFB and many questions still need to be answered. For example, teachers can benefit greatly from a comparative study of the optimal type of feedback for students at different levels of study. Such a study can also lead to the development of a sound national policy of WFB.

\subsection{Limitations}

The major limitation of the current study was that even though it investigated the provision of feedback among teachers from various disciplines, the sample of participants was not equally distributed among the four disciplines. Researchers were also unable to organize focus groups of linguistics and medicine. In addition, teachers' beliefs and practices were both enquired through a self-completed questionnaire, but analysis of their marked sample papers would have lent greater credibility to the results regarding their practices. 


\section{Conclusion}

This study affirmed the usefulness of WFB for students' learning and improvement. Moreover, intra and inter discipline variations were noted in teachers' practices of WFB. Considering the variety of factors contributing to the quality and utilization of feedback, variations in the practice of providing feedback are inevitable, but they can be minimized. Factors that influence the provision of feedback came to the fore, such as teachers' credentials and formal training for the provision of WFB, institutional culture and policies of WFB, individual student's aptitude and behavior, and finally, work overload, which in turn affects not only the quality of WFB, but also the availability of teachers to discuss the WFB. On the whole, if one considers the negligible percentage of teachers in the sample who reported having been trained in the provision of WFB, it appears that the current emphasis on pedagogy is not supplemented with an equal interest in assessment, including the quality of WFB. Therefore it is high time that faculty heads, regardless of discipline, start taking the matter seriously and organize courses and workshops on the provision of meaningful and useful feedback.

\section{Acknowledgements}

We would like to thank the Higher Education Commission of Pakistan for funding this study. In addition, we extend our appreciation to the administration of the institutions and participants of the study for their agreement and providing valuable input in the study. We are also sincerely grateful to Ms. Ambreen Gowani, for her administrative support to the project and to Ms. Yusra Husain for drafting this manuscript.

\section{References}

Bailey, J., \& Vardi, I. (1999). Iterative feedback: impacts on student writing. Paper presented at the HERDSA Annual International Conference, Australia. Retrieved from http://www.herdsa.org.au/wpcontent/upload/conference/1999/pdf/Bailey.PDF

Bailey, R., \& Garner, M. (2010). Is the feedback in higher education assessment worth the paper it is written on? Teachers' reflections on their practices. Teaching in Higher Education, 15(2), 187-198. http://dx.doi.org/10.1080/13562511003620019

Brown, G. T. L., Harris, L. R., \& Harnett, J. (2012). Teacher beliefs about feedback within an Assessment for Learning environment: Endorsement of improved learning over student well-being. Teaching and Teacher Education, 28(7). 968-978. http://dx.doi.org/10.1016/j.tate.2012.05.003.

Carless, D. (2006). Differing perceptions in the feedback process. Studies in higher education, 31(2), 219-233. http://dx.doi.org/10.1080/03075070600572132

Corcoran, J., Halverson, A. L., \& Schindler, N. (2014). A formative midterm test increases accuracy of identifying students at risk of failing a third year surgery clerkship. The American Journal of Surgery, 207(2), 260-262. http://dx.doi.org/10.1016/j.amjsurg.2013.10.009

Creswell, J. W. (2008). Qualitative inquiry and research design: Choosing among five approaches. Thousand Oaks, CA: Sage.

Fathman, A. K., \& Whalley, E. (1990). Teacher response to student writing: Focus on form versus content. In B. Kroll (Ed.), Second language writing: Research insights for the classroom (pp. 178-190). Cambridge: Cambridge University Press. http://dx.doi.org/10.1017/CBO9781139524551.016

Ferris, D. (2006). Does Error Feedback Help Student Writers? New Evidence on the Short- And Long-Term Effects of Written Error Correction. In K. Hyland and F. Hyland (Eds.), Feedback in Second Language Writing (pp. 81-104). Cambridge, England: Cambridge University Press. http://dx.doi.org/10.1017/CBO9781139524742.007

Ghazal, L., Gul, R. B., Hanzala, M., Jessop, T., \& Tharani, A. (2014). Graduate Students' Perceptions of Written Feedback at a Private University in Pakistan. International Journal of Higher Education, 3(2), 13-27. http://dx.doi.org/10.5430/ijhe.v3n2p13

Giles, T. M., Gilbert, S., \& McNeill, L. (2014). Nursing Students' Perceptions Regarding the Amount and Type of Written Feedback Required to Enhance Their Learning. The Journal of nursing education, 53(1), 23-30.

Glover, C., \& Brown, E. (2006). Written feedback for students: too much, too detailed or too incomprehensible to be effective? Bioscience Education, 7(1), 1-16. http://dx.doi.org/10.3108/beej.2006.07000004

Griffiths, C. (2007). Language learning strategies: students' and teachers' perceptions. ELT Journal, 61(2), 91-9. 
http://dx.doi.org/10.1093/elt/ccm001

Gul, M., \& Rodrigues, S. (2012). Unveiling The Focus of a Teacher's Written Feedback on Students' Composition Writing in Pakistan. International Research Journal, 1(3), 59-66.

Iqbal, S., Gul, R., Lakhani, A., \& Rizvi, F. N. (2014). Teachers' Accounts of their Perceptions and Practices of Providing Written Feedback to Nursing Students on Their Assignments. International Journal of Higher Education, 3(3), 70-80. http://dx.doi.org/10.5430/ijhe.v3n3p70

Jodaie, M. Farrokhi F., \& Zoghi M. (2011). A Comparative Study of EFL Teachers' and Intermediate High School Students' Perceptions of Written Corrective Feedback on Grammatical Errors. English Language Teaching, 4(4), 36-48. http://dx.doi.org/10.5539/elt.v4n4p36

Khowaja, A. A., \& Gul, R. B. (2014). Perceptions and Experiences of Written Feedback of Nursing Students. International Journal of Nursing Education, 6(1), 1-5. http://dx.doi.org/10.5958/j.0974-9357.6.1.001

Khowaja, A., Gul, R.B., Lakhani, A., Rizvi, N. F., \& Saleem, F. (2014). Practices of Written Feedback in Nursing Degree Programmes in Karachi: The Students Perspectives. Journal of College of Physicians and Surgeons Pakistan, 24(4), 241-244

Koh, L. C. (2010). Academic staff perspectives of formative assessment in nurse education. Nurse education in practice, 10(4), 205-209. http://dx.doi.org/10.1016/j.nepr.2009.08.007

Lee, I. (2009). Ten mismatches between teachers' beliefs and written feedback practice. ELT Journal, 63(1), 13-22. http://dx.doi.org/10.1093/elt/ccn010

Lizzio, A., \& Wilson, K. (2008). Feedback on assessment: Students' perceptions of quality and effectiveness. Assessment \& Evaluation in Higher Education, 33(3), 263-275. http://dx.doi.org/10.1080/02602930701292548

Maclellan, E. (2010). Assessment for learning: the differing perceptions of tutors and students. Assessment \& Evaluation in Higher Education, 26(4), 307-318. http://dx.doi.org/10.1080/02602930120063466

Newton, E. S. (2008). Faculty Role Modeling of Professional Writing: One Baccalaureate Nursing Program's Experience. Journal of Professional Nursing, 24(2), 80-84. http://dx.doi.org/10.1016/j.profnurs.2007.06.025

Nicol, D. (2010). From monologue to dialogue: improving written feedback processes in mass higher education, Assessment \& Evaluation in Higher Education, 35(5), 501-517. http://dx.doi.org/10.1080/02602931003786559

Orrell, J. (2006). Feedback on learning achievement: rhetoric and reality. Teaching in Higher Education, 11(4), 441-456. http://dx.doi.org/10.1080/13562510600874235

Poulos, A., \& Mahony, M. J. (2008). Effectiveness of feedback: the students' perspective. Assessment \& Evaluation in Higher Education, 33(2), 143-154. http://dx.doi.org/10.1080/02602930601127869

Rogers, D. A., Boehler, M. L., Schwind, C. J., Meier, A. H., Wall, J. C., \& Brenner, M. J. (2012). Engaging medical students in the feedback process. The American Journal of Surgery, 203(1), 21-25. http://dx.doi.org/10.1016/j.amjsurg.2011.07.009

Schartel, S. A. (2012). Giving feedback - An integral part of education. Best Practice \& Research Clinical Anaesthesiology, 26(1), 77-87. http://dx.doi.org/10.1016/j.bpa.2012.02.003 